\title{
Analisa Perilaku Dosen dalam Memanfaatkan E-Learning di Lingkungan PNJ Menggunakan TAM2 (Technology Acceptance Model)
}

\author{
Anita Hidayati, Shinta Oktaviana, Iklima Ermis Ismail \\ Prodi Teknik Informatika \\ Jurusan Teknik Informatika dan Ko mputer, Po liteknik Negeri Jakarta \\ Jalan Prof. G.E. Siwabessy, Kampus UI, Depok, Jawa Barat \\ Anita.hidayati@tik.pnj.ac.id, shinta.oktaviana@tik.pnj.ac.id, iklimaermis.is mail@tik.pnj.ac.id
}

Diterima: 13 Oktober 2017. Disetujui 15 Oktober 2017. Dipublikasikan Nove mber 2017

\begin{abstract}
Abstrak - E-learning merupakan salah satu penunjang keberhasilan proses pembelajaran dalam hal peningkatan mutu dan kualitas. Penelitian ini bertujuan untuk menganalisa perilaku dosen dalam memanfaatkan E-learning dengan TAM2 (Technology Acceptance Model). Metode TAM2 digunakan untuk mengukur tingkat penerimaan teknologi pada sebuah organisasi. Instrumen penelitian berupa kuisioner online dalam bentuk google form yang disebarkan kepada dosen semua jurusan di PNJ. Kuesioner yang bisa diolah sebanyak 22 data. Model diolah menggunakan SEM (Structural Equation Model), dan hasil kuesioner diolah menggunakan tools SmartPLS. Hasil pengolahan data menunjukkan bahwa dosen di PNJ belum dapat menerima kehadiran e-learning sebagai media pembelajaran. Beberapa penyebab kondisi ini adalah belum terbangunnya budaya organisasi dalam menggunakan e-learning sebagai sarana untuk membantu proses belajar mengajar; belum terintegrasinya e-learning dengan sistem informasi akademik dan data akademik; user interface e-learning yang masih kurang sesuai dengan kebutuhan dan kondisi dosen PNJ.
\end{abstract}

Kata Kunci: e-learning, tam2, sem, hipotesa, pnj.

\section{PENDAHULUAN}

Politeknik Negeri Jakarta (PNJ) sebagai salah satu institusi yang berbasis teknologi informasi, telah menerapkan sistem e-learning selama beberapa tahun terakhir. E-learning bertujuan untuk menunjang kegiatan akademik dan pembelajaran. Setelah dilakukan observasi, diperoleh hasil bahwa pemanfaatan e-learning sebagai media pembelajaran oleh dosen di PNJ belu m optimal. Hal tersebut dapat dilihat dari jumlah modul yang saat ini terdapat di $e$ learning seperti pada Tabel 1. Sedikitnya jumlah modul yang ada mengindikasikan bahwa tingkat partisipasi penggunaan e-learning oleh dosen masih rendah.
TABEL 1. DATA MODUL DI E-LEARNING

\begin{tabular}{|l|c|}
\hline \multicolumn{1}{|c|}{ Jurusan } & Jumlah Modul \\
\hline Administrasi Bisnis & 0 \\
\hline Teknik Sipil & 0 \\
\hline Teknik Mesin & 6 \\
\hline Akuntansi & 0 \\
\hline Teknik Elektro & 7 \\
\hline Teknik Grafika dan Penerbitan & 1 \\
\hline $\begin{array}{l}\text { Teknik Informat ika dan } \\
\text { Komputer }\end{array}$ & 3 \\
\hline
\end{tabular}

Hal ini yang memotivasi Peneliti untuk melakukan analisa perilaku dosen dalam memanfaatkan $e$ learning di lingkungan PNJ. Dosen dipilih sebagai obyek penelitian karena mereka merupakan ujung tombak dalam menyukseskan e-learning. Ketika dosen aktif memanfaatkan e-learning maka mahasiswa secara otomatis juga akan aktif menggunakan e-learning. Tingginya interaksi penggunaan e-learning akan meningkatkan mutu dan kualitas pembelajaran.

Hasil dari penelitian ini berupa analisis dan saran untuk me maksimalkan pemanfaatan e-learning di lingkungan PNJ yang diharapkan dapat men ingkatkan intensitas penggunaan e-learning oleh dosen dalam proses pembelajaran.

\section{TEORI PENUNJANG}

\section{A. Technology Acceptance Model (TAM)}

TAM pertama kali diperkenalkan oleh Dav is pada tahun 1989, teori ini dimulai dengan membuktikan bawah perilaku seseorang dapat berubah[1]. Saat ini TAM sebagai model yang paling banyak digunakan dalam menilai seberapa jauh penerimaan pengguna terhadap suatu sistem informasi dilihat dari perubahan perilaku[2-5].

Terdapat 2 faktor utama yang digunakan dalam TAM yaitu faktor kegunaan sistem informasi 
bagi pengguna dan faktor kemudahan menggunakan sistem informasi oleh pengguna, masing-masing faktor dievaluasi menggunakan variabel eksternal. Beberapa variabel eksternal yang digunakan diantaranya variabel sosial, variabel budaya, dan variabel politik. Variabel sosial meliputi bahasa, keterampilan, dan fasilitas penunjang. Variabel budaya berkaitan dengan kebiasaan atau perilaku sementara variabel politik contohnya pengaruh dari implementasi sistem informasi dari sisi kebijakan[1].

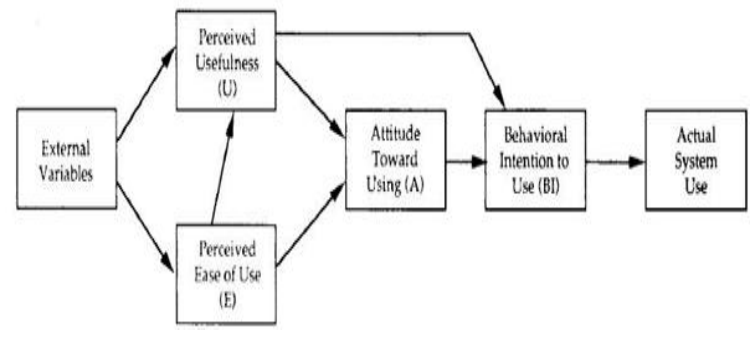

Gambar 1. ModelTAM

Self-efficacy merupakan faktor yang berpengaruh secara tidak langsung pada keinginan siswa melalui rasa kemudahan penggunaan[6]. Mungania dan Reio menemukan hubungan yang signifikan antara halangan disposisi dan selfefficacy e-learning. Self-efficacy merupakan kepercayaan diri individu dalam menemukan informasi dan berkomun ikasi dengan instruktur pada sistem e-learning dan keahlian yang diperlukan untuk menggunakan sistem[7].

Model TAM2 merupakan pengembangan dari model TAM. Penekanannya adalah pada Faktor Eksternal. Pada model TAM2, norma subjektif merupakan salah satu variable yang berpengaruh mengacu pada tekanan sosial untuk menampilkan atau tidak menampilkan perilaku [6].

Malhotra dan Galletta, juga menyatakan bahwa penting untuk melihat bagaimana pengaruhpengaruh sosial mempengaruhi komitmen pengguna untuk menggunakan sistem informasi dalam memahami, menjelaskan dan memprediksi penggunaan sistem dan sikap penerimaan dari pengguna[9]. Grandon, Alshare dan Kwan mengemukakan bahwa norma subjektif juga merupakan faktor yang berpengaruh signifikan pada keinginan siswa menggunakan e-learning[6]. Secara berkebalikan, Ndubisi mengemukakan bahwa norma subjektif tidak memiliki pengaruh signifikan pada keinginan siswa menggunakan e-learning[10].

Variabel-variabel yang berkaitan dengan keinginan menggunakan teknologi informasi atau penggunaan teknologi informasi dapat dikelompokkan menjadi empat kategori, yatiu : konteks individual, konteks sistem, konteks sosial, dan konteks organisasi. Konteks sosial merupakan pengaruh sosial pada penerimaan individu terhadap penggunaan teknologi informasi. Konteks organisasi menekankan pengaruh atau dukungan organisasi terhadap penggunaan teknologi informasi. Thong, Hong dan Tam mengidentifikasi hubungan, visibilitas sistem, dan kemudahan akses atau aksesibilitas sistem sebagai variabel-variabel pada konteks organisasi. Mereka mengemukakan bahwa konteks organisasi mempengaruhi rasa kemanfaatan dan rasa kemudahan penggunaan pada sebuah perpustakaan digital[11]. Lin dan Liu menyatakan hal yang sama pada penelitian mereka, menyatakan bahwa semakin tinggi kemudahan akses informasi maka akan semakin tinggi penggunaan informasi dan juga semakin tinggi persepsi kemudahan penggunaan[12].

\section{B. E-learning}

E-learning merupakan sebuah sistem yang menyediakan akses dan pembelajaran secara online. Berkembangnya e-learning merupakan trend yang dipengaruhi oleh faktor demografi siswa, pertukaran informasi dan inovasi teknologi[13] Meskipun banyak institusi pendidikan gagal menerapkan $e$ learning karena biaya teknologi yang tinggi, lemahnya keputusan, kompetisi dan tidak adanya strategi bisnis, banyak perguruan menghadapi kesulitan dalam mencapai strategi keberhasilan termasuk pengiriman, keefektifan dan penerimaan oleh pengguna[14]. E-learning menawarkan pembelajaran dan berusaha mereplikasi pengalaman ruangan kelas secara online, namun tidak berhasil menemukan kebutuhan siswa dan menyebabkan kegagalan[15]. Suksesnya e-learning didasarkan pada banyaknya waktu pembelajaran menggunakan e-learning yang dihabiskan oleh pengguna[16]. Kesiapan pengguna untuk menggunakan teknologi e-learning juga berpengaruh besar pada keberhasilan e-learning suatu organisasi[17].

\section{METODOLOGI PENELITIAN}

\section{A. Hipotesis Penelitian}

Berdasarkan teori literatur dan tujuan penelitian, maka pada penelitian ini terdapat beberapa hipotesis yang akan dibuktikan:

1. $\mathbf{H}_{\mathbf{1}}$ : Keinginan pengajar untuk memanfaatkan $e$ learning dipengaruhi oleh sikap (attitude), rasa kemanfaatan (perceived usefulness), rasa kemudahan dalam penggunaan (perceived ease of use), keyakinan diri (self-efficacy), norma sujektif (subjective norm), dan kemampuan akses sistem (system accessibility).

2. $\mathbf{H}_{2}$ : Sikap pengajar dalam memanfaatkan $e$ learning dipengaruhi oleh rasa kemanfaatan (perceived usefulness), rasa kemudahan dalam penggunaan (perceived ease of use), keyakinan diri (self-efficacy), norma subjektif (subjective 
norm), dan kemampuan akses sistem (system accessibility).

3. $\mathbf{H}_{3}$ : Rasa kemanfaatan e-learning bagi pengajar dipengaruhi oleh rasa kemudahan dalam penggunaan (perceived ease of use), keyakinan diri (self-efficacy), norma sujektif (subjective norm), dan kemampuan akses sistem (system accessibility).

4. $\mathbf{H}_{4}$ : Rasa kemudahan dalam penggunaan $e$ learning bagi pengajar dipengaruhi oleh, keyakinan diri (self-efficacy), norma sujektif (subjective norm), dan kemampuan akses sistem (system accessibility).

\section{B. Desain Penelitian}

Berdasarkan model TAM dan hipotesis yang diusulkan, maka model penelitian akan diuji dan dianalisa seperti pada Gambar 2.

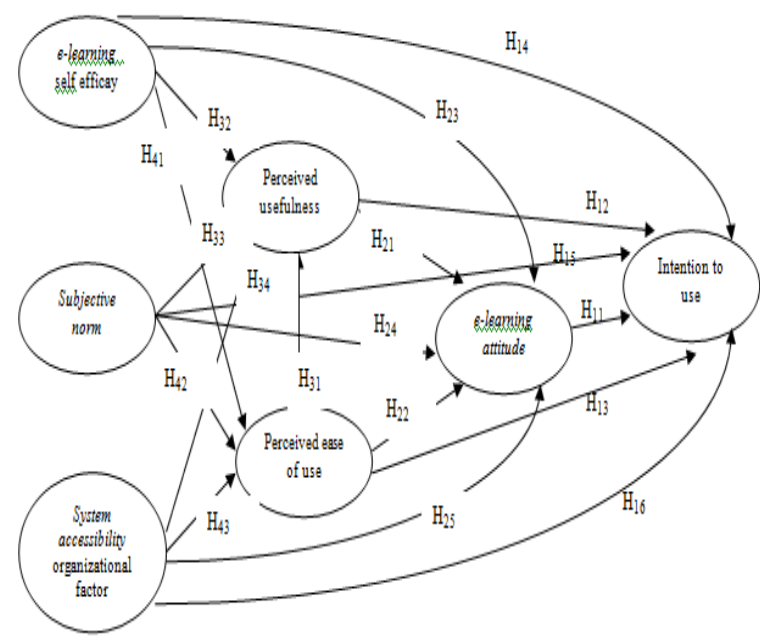

Gambar 2. Desain Penelitian

\section{Metode Pengujian Desain Penelitian}

Pendekatan yang digunakan pada penelitian ini adalah pendekatan kuantitatif. Hal ini karena desain penelitian yang digunakan dalam bentuk angka (numerik) dan bentuk hipotesis, sehingga menggunakan analisis kuantitatif deskriptif dan analisis kuantitatif inferensial untuk menguji hipotes is yang diusulkan.

Instrumen penelitian berupa kuesioner yang disusun secara terstruktur, dibuat dalam bentuk pernyataan tertutup dan menggunakan jawaban dengan skala likert 5 level, dimana : 1= Sangat Tidak Setuju (STS), 2= Tidak Setuju (TS), 3= Netral (N), 4= Setuju (S), 5= Sangat Setuju (SS). Jawaban dari responden akan menjadi data yang kemudian akan dianalisa. Penyebaran kuesioner akan dilakukan kepada 100 orang responden. Responden disini adalah dosen di lingkungan Politeknik Negeri Jakarta.

Data kuesioner direkapitulasi menggunakan Microsoft Excel dan SPSS. Metode yang akan digunakan adalah model Structural Equation Modelling (SEM) dengan bantuan tools AMOS. Tahapan penelitian ditunjukkan pada Gambar 3.

Merumuskan Masalah

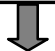

Melakukan Studi Literatur

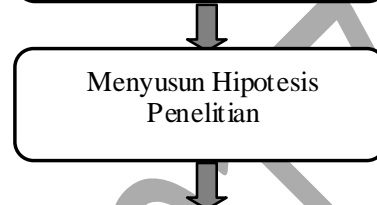

Menyusun Model

Kerangka Konsep

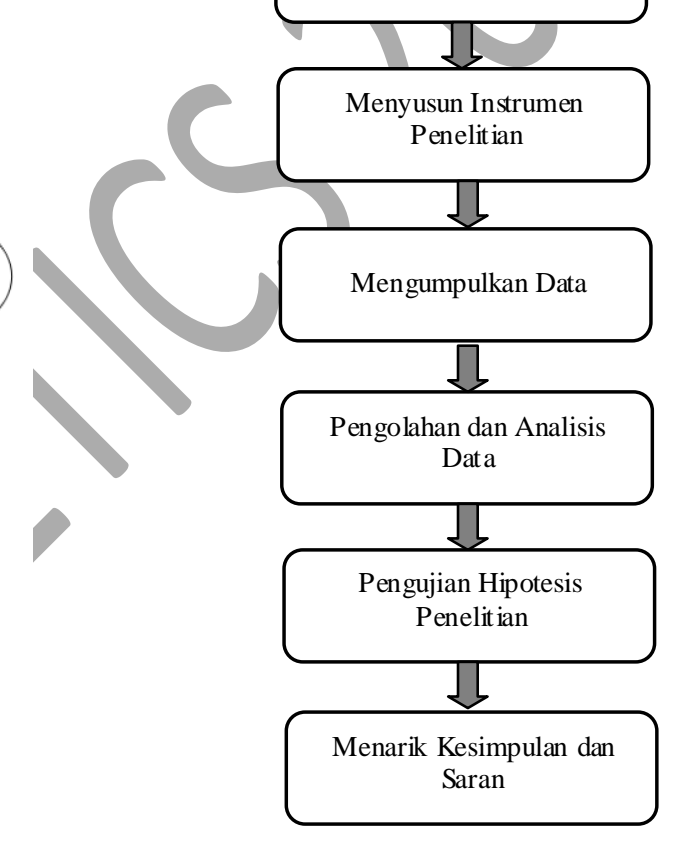

Gambar 3. Alur Penelitian

\section{HASIL DAN PEMBAHASAN}

\section{A. Menyusun Instrumentasi Penelitian}

Berdasarkan analisis dan studi literatur dengan penelitian sejenis, maka kuesioner yang disusun untuk merepresentasikan model penelitian terdiri dari beberapa bagian pernyataan :

- Perceived Ease of Use (PEOU) atau rasa kemudahan dalam penggunaan e-learning

- Perceived Usefullness (PU) atau rasa kemanfaatan e-learning

- Attitude (AT) atau sikap dalam menggunakan $e$ learning 
- Intention to Use (IU) atau keinginan yang mendorong tingkah laku menggunakan $e$ learning

- Self Efficacy (SE) atau keyakinan pribadi dosen mampu menggunakan e-learning

- Subjective Norm (SN) atau norma subjektif

- System Accessibility (SA) atau kemampuan akses sistem

\section{B. Mengumpulkan Data}

Penyebaran kuesioner dilakukan secara online dengan menyebarkan link google form dalam waktu 2 bulan kepada dosen-dosen yang mengampu mata kuliah pada semua jurusan di PNJ. Data kuesioner yang diperoleh sebanyak 34 responden.

\section{Hasil Pengolahan dan Analisis Data}

Proses pembersihan data (cleansing) terhadap data dengan missing value lebih dari 5\%. sehingga jumlah data yang bisa diolah sebagai sampel sebanyak 22 data responden $(64,7 \%)$. Data ini menunjukkan masih rendahnya tingkat pengguna $e$ learning di PNJ. Data dalam format .xls kemudian diolah menggunakan SmartPLS.

Berikut adalah relasi hipotesis ntuk pengujian hipotes is sesuai dengan Gambar 4.

- $\mathrm{H}_{1}$ : IU dipengaruhi oleh $\mathrm{AT}\left(\mathrm{H}_{11}\right), \mathrm{PU}\left(\mathrm{H}_{12}\right)$, PEOU $\left(\mathrm{H}_{13}\right), \quad \mathrm{SE}\left(\mathrm{H}_{14}\right), \quad \mathrm{SN}\left(\mathrm{H}_{15}\right)$ dan $\mathrm{SA}$ $\left(\mathrm{H}_{16}\right)$.

- $\mathrm{H}_{2}$ : AT dipengaruhi oleh $\mathrm{PU}\left(\mathrm{H}_{21}\right), \operatorname{PEOU}\left(\mathrm{H}_{22}\right)$, $\mathrm{SE}\left(\mathrm{H}_{23}\right), \mathrm{SN}\left(\mathrm{H}_{24}\right)$ dan $\mathrm{SA}\left(\mathrm{H}_{15}\right)$

- $\mathrm{H}_{3}$ : PU dipengaruhi oleh PEOU $\left(\mathrm{H}_{31}\right), \mathrm{SE}\left(\mathrm{H}_{32}\right)$, $\mathrm{SN}\left(\mathrm{H}_{33}\right)$ dan $\mathrm{SA}\left(\mathrm{H}_{34}\right)$

- $\mathrm{H}_{2}$ : PEOU dipengaruhi oleh $\mathrm{SE}\left(\mathrm{H}_{41}\right), \mathrm{SN}\left(\mathrm{H}_{42}\right)$ dan $\mathrm{SA}\left(\mathrm{H}_{23}\right)$

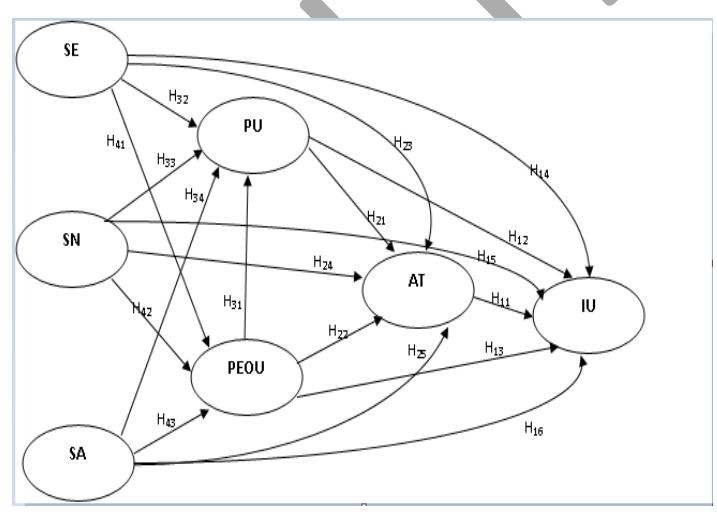

Gambar 4. Desain Penelitian
Desain penelitian beserta relasi hipotesis dibentuk menjadi diagram jalur menggunakan SmartPLS. Diagram jalur diolah menggunakan inputan yang diperoleh dari data kuesioner dan diperoleh hasil untuk setiap relasi dan faktor loading, seperti yang terdapat pada Gambar 5 .

Pada Pada diagram jalur, setiap pernyataan pada kuesioner akan menjadi indikator refleksif. Faktor-faktor akan menjadi konstruk, dan akan dihitung bobot untuk masing-masing relasi hipotesis

Konstruk dengan indikator refleksif dikatakan valid jika nilai faktor loading $>0,70$. Pada Gambar 5, terdapat hanya satu faktor loading yang nilainya tidak valid, yaitu Subjective norm (SN3), dengan nilai 0,313. Faktor loading yang lain dapat dikatakan valid, karena memiliki nilai diatas 0,70 .

TABEL 2. HASIL AVE, COMPOSITE RELIABILITY, CRONBACHS ALPHA, DAN COMMUNALITY

\begin{tabular}{|c|c|c|c|c|}
\hline & AVE & $\begin{array}{c}\text { Composite } \\
\text { Reliability }\end{array}$ & $\begin{array}{c}\text { Cronbachs } \\
\text { Alpha }\end{array}$ & $\begin{array}{c}\text { Commu } \\
\text { nality }\end{array}$ \\
\hline AT & 0.715775 & 0.882724 & 0.799214 & 0.715775 \\
\hline IU & 0.874139 & 0.93284 & 0.856377 & 0.874139 \\
\hline PEOU & 0.841906 & 0.941062 & 0.907028 & 0.841906 \\
\hline PU & 0.838112 & 0.939497 & 0.90378 & 0.838112 \\
\hline SA & 1 & 1 & 1 & 1 \\
\hline SE & 0.74372 & 0.852026 & 0.677414 & 0.74372 \\
\hline SN & 0.548847 & 0.760455 & 0.577234 & 0.548846 \\
\hline
\end{tabular}

Konstruk dapat dikatakan memenuhi validitas konvergen jika nilai A VE dan Communality yang dihasilkan konstruk >0.50 (Chin, 1998) [18]. Se mua konstruk menghasilkan nilai A VE dan Communality $>0.50$, sehingga semua konstruk pada penelitian in $\mathrm{i}$ sudah memenuhi validitas.

Untuk memenuhi uji reliabilitas, dilihat dari nilai Cronbachs Alpha. Jika Cronbachs Alpha > 0.70, konstruk dapat dikatakan reliabel (Chin, 1998)[18]. Namun, pada PLS lebih disarankan untuk menggunakan Composite Reliability (Latan, 2012)[19]. Nilai Composite Reliability yang dihasilkan oleh semua konstruk $>0.70$, sehingga semua konstruk memenuhi uji reliabilitas.

\section{Pengujian Hipotesis Penelitian}

Pengujian hipotesis dilakukan dengan memperhatikan nilai Relasi Coefficient (Mean, STDDEV, T-Values) pada kolom T-statistik. Mengacu pada aturan pengukuran signifikansi dari Chin(1998), jika nilai T-statistik > 1,96, maka berarti indikator tersebut valid[18]. Hasil uji hipotesis terdapat pada Tabel 3. 


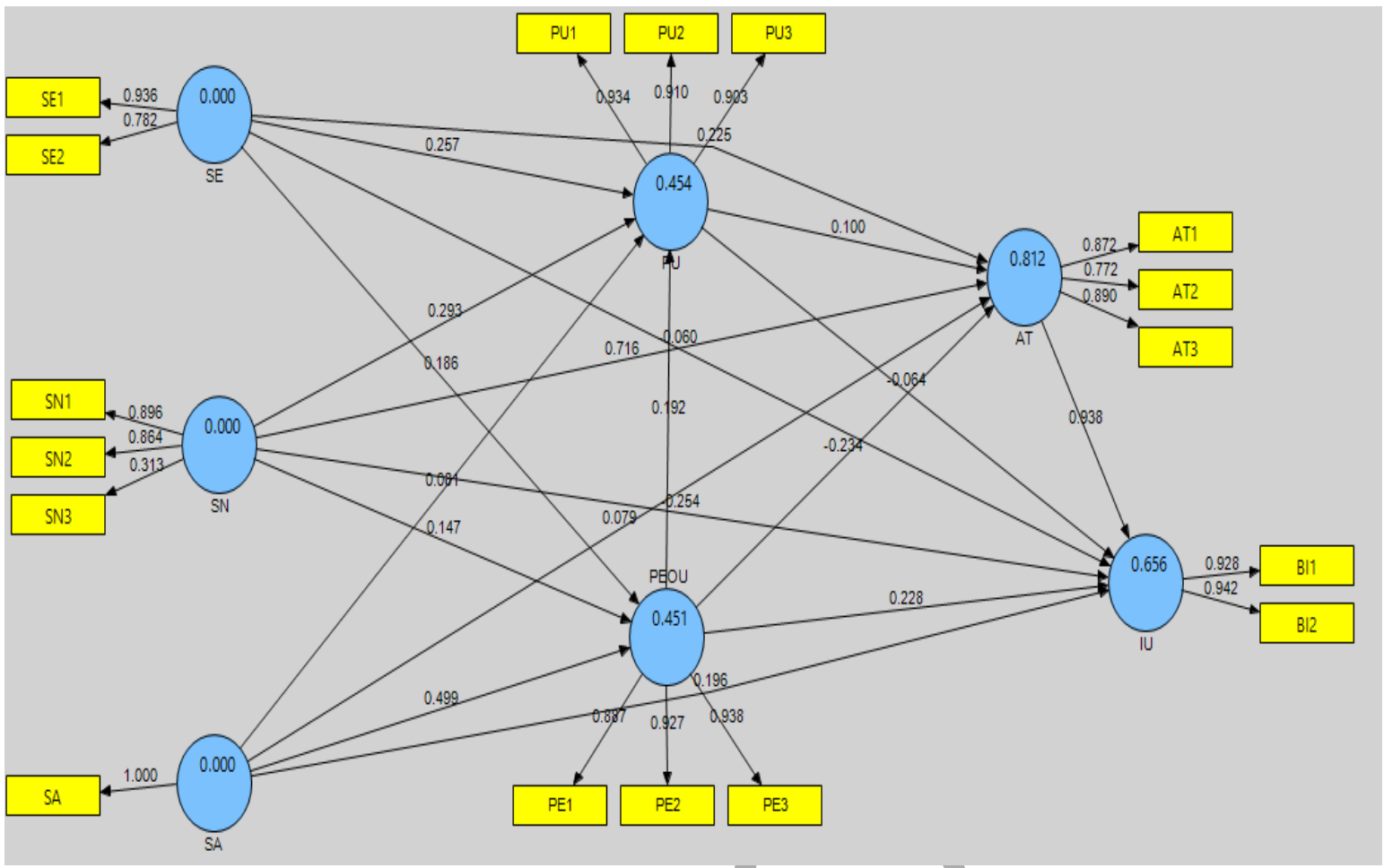

Gambar 5. Diagram Jalur dengan Faktor Loading

TABEL 3. RELASI COEFFICIENT (MEAN, STDEV, T-VALUES)

\begin{tabular}{|c|c|c|c|c|c|c|c|}
\hline Hipotesis & $\begin{array}{c}\text { Faktor } \\
\text { Loading }\end{array}$ & $\begin{array}{c}\text { Original } \\
\text { Sample (O) }\end{array}$ & $\begin{array}{c}\text { Sample } \\
\text { Mean (M) }\end{array}$ & $\begin{array}{l}\text { Standard } \\
\text { De viation } \\
\text { (STDEV) } \\
\end{array}$ & $\begin{array}{c}\text { Standard } \\
\text { Error } \\
\text { (STERR) } \\
\end{array}$ & $\begin{array}{c}\text { TS Statistics } \\
\text { (|OS TERR } \mid)\end{array}$ & Ke terangan \\
\hline \multicolumn{8}{|c|}{ H1 } \\
\hline H11 & AT $>$ IU & 0.937903 & 0.926277 & 0.153892 & 0.153892 & 6.094562 & Diterima \\
\hline H12 & PU -> IU & -0.063526 & -0.042 & 0.110422 & 0.110422 & 0.575305 & Ditolak \\
\hline H13 & PEOU -> IU & 0.227915 & 0.225712 & 0.102856 & 0.102856 & 2.215863 & Diterima \\
\hline H14 & SE -> IU & -0.060446 & -0.04565 & 0.13385 & 0.13385 & 0.451596 & Ditolak \\
\hline H15 & SN $->$ IU & -0.253614 & -0.27909 & 0.204515 & 0.204515 & 1.240079 & Ditolak \\
\hline H16 & SA $\rightarrow$ IU & 0.195799 & 0.19269 & 0.069837 & 0.069837 & 2.803652 & Diterima \\
\hline \multicolumn{8}{|c|}{$\mathrm{H} 2$} \\
\hline H21 & $\overline{\mathrm{PU}} \rightarrow \mathrm{AT}$ & 0.10028 & 0.100957 & 0.082743 & 0.082743 & 1.211938 & Ditolak \\
\hline H22 & $\begin{array}{c}\text { PEOU -> } \\
\text { AT }\end{array}$ & -0.233942 & -0.23571 & 0.076492 & 0.076492 & 3.058364 & Diterima \\
\hline $\mathrm{H} 23$ & $\mathrm{SE} \rightarrow \mathrm{AT}$ & 0.225404 & 0.233149 & 0.100098 & 0.100098 & 2.251838 & Diterima \\
\hline H24 & SN $\rightarrow$ AT & 0.716241 & 0.712665 & 0.072243 & 0.072243 & 9.914297 & $\overline{\text { Diterima }}$ \\
\hline $\mathrm{H25}$ & SA $\rightarrow$ AT & 0.079476 & 0.076285 & 0.064651 & 0.064651 & 1.229296 & Ditolak \\
\hline \multicolumn{8}{|c|}{ H3 } \\
\hline H31 & PEOU -> PU & 0.19246 & 0.156917 & 0.128115 & 0.128115 & 1.502245 & Ditolak \\
\hline H32 & $\mathrm{SE}->\mathrm{PU}$ & 0.256795 & 0.26278 & 0.151284 & 0.151284 & 1.697433 & Ditolak \\
\hline H33 & SN $>P U$ & 0.292877 & 0.308234 & 0.127772 & 0.127772 & 2.292179 & Diterima \\
\hline H34 & SA -> PU & 0.081249 & 0.10264 & 0.111229 & 0.111229 & 0.730467 & Ditolak \\
\hline \multicolumn{8}{|c|}{ H4 } \\
\hline H41 & SE -> PEOU & 0.185546 & 0.204319 & 0.14293 & 0.14293 & 1.298164 & Ditolak \\
\hline $\mathbf{H 4 2}$ & SN -> PEOU & 0.146908 & 0.140218 & 0.15238 & 0.15238 & 0.96409 & Ditolak \\
\hline $\mathbf{H 4 3}$ & SA -> PEOU & 0.499425 & 0.497995 & 0.062599 & 0.062599 & 7.978116 & Diterima \\
\hline
\end{tabular}

Berdasarkan Tabel 3, diperoleh perhitungan untuk relasi dari hipotesis. Terdapat delapan relasi yang diterima, dan sepuluh relasi yang ditolak.

\section{KESIMPULAN DAN SARAN}

\section{A. Kesimpulan}

Telah dilakukan pengujian untuk mengetahui perilaku dosen dalam memanfaatkan e-learning di PNJ dengan menggunakan model TAM2 
(Technology Acceptance Model). Berdasarkan hasil pengujian dan analisis hipotesis, maka dapat diambil kesimpulan sebagai berikut:

1. Keinginan pengajar untuk memanfaatkan elearning di PNJ dipengaruhi oleh sikap (attitude), rasa kemudahan dalam penggunaan (perceived ease of use) dan kemampuan akses sistem (system accessibility).

2. Sikap pengajar/dosen di PNJ dalam memanfaatkan e-learning dipengaruhi oleh rasa kemudahan dalam penggunaan (perceived ease of use), keyakinan diri (self-efficacy), norma sujektif (subjective norm).

3. Rasa kemanfaatan e-learning bagi pengajar di PNJ dipengaruhi oleh norma sujekt if (subjective norm).

4. Rasa kemudahan dalam penggunaan e-learning bagi pengajar di PNJ dipengaruhi oleh ke mampuan akses sistem (system accessibility).

\section{B. Saran}

Berdasarkan hasil penelitian, diusulkan beberapa saran, yaitu:

1. Perlu dilakukan sosialisasi kepada para dosen tentang peran dan urgensi menggunakan $e$ learning sebagai media bantu proses belajar mengajar, karena masih sedikitnya responden yang sudah menggunakan e-learning .

2. Perlu adanya suatu kebijakan dari sisi organisasi untuk menjadikan penggunaan e-learning sebagai budaya organisasi.

3. Perlu adanya perbaikan dari sisi user-interface elearning yang ada di PNJ yang bisa menyesuaikan dengan kondisi pengguna, sehingga dosen PNJ, yang sebagian besar merupakan dosen senior, tidak terlalu kesulitan dalam menggunakan e-learning PNJ.

4. Perlu adanya integrasi e-learning dengan sistem informasi akademik, dan menggunakan mekanis me Single Sign On (SSO).

\section{REFERENSI}

[1] D. Davis Jr. 1986. A Technology Acceptance Model for Empirically Testing New End-user Information Systems: Theory and Results. USA : Massachusetts Institute of Technology

[2] K. A. Al-Busaidi and H. Al-Shihi. 2010.Instructors' Acceptance of Learning Management Systems: A Theoretical Framework. Communications of the IBIMA, vol. 2010, p. 2010.

[3] Q. Ma and L. Liu. 2004.The Technology Acceptance Model: A Meta-Analysis Of Empirical Findings. Journal of Organizational and End User Computing (JOEUC), vol. 16, pp. 59-72.

[4] Kim and H. Chang. 2007. Key Functional Characteristics in Designing And Operating Health Information Websites for User Satisfaction: An Application of The Extended Technology Acceptance Model. International Journal of Medical Informatics, vol. 76, pp. 790-800.
[5] J.-W. Moon and Y.-G. Kim. 2001. Extending The T AM for a World-WideWeb Context. Information \& Management, vol. 38, pp. 217-230.

[6] Grandon, E., Alshare, O., \& Kwan, O. 2005. Factors influencing student intention to adopt online classes: A cross-cultural study. Journal of Computing Sciences in Colleges, 20(4), 46-56.

[7] Mungania, P., \& Reio, Jr. T. G. 2005. If e-learners get there, will they stay? The role of e-learning self-efficacy. Eric ed492287. Paper presented at the Academy of Human Resource Development International Conference (AHRD), Estes Park, CO, Feb 24-27, 2005, p. 1110-1117 (Symp. 48-2).

[8] Ajzen, I. 1991. The theory of planned behavior Organizational Behavior and Human Decision Processes, $50,179-211$.

[9] Malhotra, Y., \& Galletta, D. F. 1999. Extending the technology acceptance model to account for social influence: Theoretical bases and empirical validation. Proceedings of the 32nd Hawaii International Conference on System Sciences

[10] Ndubisi, N. O. 2006. Factors of online learning adoption: A comparative juxtaposition of the theory of planned behavior and the technology acceptance model. International Journal on E-learning, 5(4), 571-591.

[11] Thong, J. Y. L., Hong, W., Tam, K. 2002. Understanding user accept ance of digital libraries: What are the roles of interface characteristics, organizational context, and individual differences? International Journal of HumanComputer Studies, 57, 215-242.

[12] Lin, J. C., \& Lu, H. 2000. Towards an understanding of the behavioral intention to use a Web Site. International Journal of Informat ion Management, 20, 197-208.

[13] Concannon, F., Flynn A., \& Campbell. 2005. What campus-based students think about the quality and benefits of e-learning. British Journal of Educational Technology. $36(2), 501-512$.

[14] Saadé, R. G. 2003. Web-based education information system for enhanced learning, EISL: Student assessment. Journal of Informat ion Technology Education, 2, 267-277.

[15] Kilmurray, J. (2003). E-learning: It's more than automation. The Technology Source archives. Retrieved April 20, 2007, from http:/technologysource.org/article/elearning/.

[16] Romero, M., \& Barbera, E. 2011. Quality of learners time and learning performance beyond quantitative time-ontask. The International Review of Research in Open and Distance Learning, 5, 125-137.

[17] Bayu,Henki.,Wati, T.,Matondang, N., 2016. Analisis Pengukuran Tingkat KEsiapan Implementasi E-learning (E-learning Readiness) Studi Kasus : UPN Veteran Jakarta Seminar Nasional Teknologi Informasi dan Multimedia. 2.5-1 s.d. 2.5-6.

[18] Chin, W. W., .1998. The Partial Least Squares Approach for Structural Equation Modeling, in G.A. Marcoulides (Ed.), Modern Methods for Business Research (pp. 295236). London: Lawrence Elbaum Association.

[19] Latan, H., dan Ghozali, I., 2012. Partial Least Square Konsep. Teknik dan Aplikasi Menggunakan Program SmartPLS 2.0 M3. Semarang: Badan Penerbit Universitas Diponegoro. 